\title{
The Entrepreneurial Orientation (EO) of Incubators, Accelerators, and Co-working Spaces
}

\author{
Drew Gertner \\ B15 2TT Birmingham, United Kingdom \\ E-mail: d.gertner@bham.ac.uk \\ Elizabeth A. Mack (Corresponding author) \\ Department of Geography, the Environment and Spatial Sciences, Michigan State \\ University, United States \\ E-mail: emack@msu.edu
}

Received: February 16, 2017

Accepted: April 15, 2017

Published: May 20, 2017

doi:10.5296/ijrd.v4i2.10210

URL: http://dx.doi.org/10.5296/ijrd.v4i2.10210

\begin{abstract}
The concept of entrepreneurial orientation (EO) is widely accepted as a significant theory in the literature on firm-level entrepreneurship. Despite the collectivity of research, which continues to demonstrate that entrepreneurship and EO differ in nature and according to context, too often, context is ignored. To address this gap, this paper proposes a conceptual framework based on three suddimensions of EO (innovativeness, risk-taking and proactiveness) and a qualitative, multiple case study approach that incorporates data from semi-structured interviews with facility managers and photographic data from incubation facilities to analyze differences in the EO of different types of organizational contexts that provide business support to entrepreneurs such as incubators, accelerators and co-working spaces. Analytical results highlight variations in EO by business support facilities related to their organizational context and the subdimension of EO considered. Combined, these results highlight the need for discriminating amongst different dimensions when examining EO, as well as the need for some new indicators or measurements of each dimension.
\end{abstract}

Keywords: Entrepreneurial Orientation, Incubators, Accelerators, Co-Working Spaces, Business Support, New Venture Creation, Organizational Context

\section{Introduction}

Business incubators are designed to provide low-rent office space (Markley and McNamara 1995) and support services (Scillitoe and Chakrabarti 2010, Vanderstraeten and Matthyssens 
2012) to help new ventures grow and create jobs (Markley and McNamara, 1995). Since the first business incubator opened in 1959, a number of variations on this idea have emerged including co-working spaces and startup accelerators. Some fundamental goals of co-working spaces are to foster serendipitous contacts between entrepreneurs (Cashman 2012, Moriset 2014) and to build a sense of community (Cashman, 2012). In this sense, co-working spaces are fundamentally creative and collaboration-oriented spaces (Hubbard, 2013) and feature more peer-to-peer mentorship than the other types of spaces (Harrison, 2012).

The primary goal of startup accelerators is quite different from both traditional incubators and co-working spaces. Accelerators are designed to accelerate the growth of companies in their portfolio (Fankhauser, 2013) by providing entrepreneurs with a host of resources in exchange for a share of stock in the venture (Cohen and Hochberg 2014). The types of resources provided include access to mentor networks, access to technology, office space, and access to the entrepreneurial community (Frankhauser, 2013). Ventures are chosen via a rigorous selection process, and move through the accelerator's program in cohorts (Miller and Bound, 2011). One of the critical selection criteria is the strength of the new venture's team rather than the expertise of a single founder (Miller and Bound 2011).

Recent statistics of incubation activity estimate that there are over 7,000 business incubators (NBIA, 2016), 387 startup accelerators (Gust, 2015), and 7,800 coworking spaces around the globe (Foertsch, 2015). While there is general agreement about the importance of these facilities to nurturing entrepreneurial activity surprisingly little is known about these organizations, which behave like firms in that they manage a portfolio of assets in the form of new ventures to achieve their primary organizational objective of maximizing venture competitiveness and survival. This is especially true regarding the entrepreneurial orientation of different types of entrepreneurial support spaces, and their diverse strategies for managing their portfolio of firms. The extent that these facilities differ, particularly as regards the various subdimensions of entrepreneurial orientation (proactivenesss, risk-taking, and innovativeness) remains unevaluated in either the business incubation, entrepreneurship, or entrepreneurial orientation literature.

Given this research need, this paper will test the following two hypotheses: 1 . There are differences in the EO of different types of entrepreneurial support spaces such as incubators, accelerators and co-working spaces; 2. Differences in the EO of entrepreneurial support spaces varies across subdimensions of EO. An examination of these hypotheses makes several contributions to research on entrepreneurship and entrepreneurial orientation. First, it provides an understanding of differences in the manifestation of EO across distinct organizational contexts that provide business support to entrepreneurs and the factors underlying these differences. Second, it contributes to the methodological gap that there are "too few qualitative studies" in the EO literature by adopting a qualitative approach to further understand the EO construct (Miller 2011, p. 878). A qualitative approach enables us to move beyond simplistic questions of the "who, what, where and when" of EO to provide a more nuanced understanding of the why and how of EO (ibid: 887). Third, the paper provides a comparative perspective on entrepreneurial spaces, which to this point, has focused on studying incubated firms (Clausen \& Korneliussen 2012). Given that recent research has 
highlighted that the EO of entrepreneurial spaces influences the success of incubation, it is essential to understand how EO manifests itself across different types of incubation spaces.

\section{Entrepreneurial Orientation}

The EO concept emerged in the 1980s from the pioneering research of Miller (1983). It can be defined as "the extent to which the top managers are inclined to take business-related risks, to favor change and innovation in order to obtain a competitive advantage for their firm, and to compete aggressively with other firms" (Covin \& Slevin, 1989, p. 77). It is a construct used to capture the degree that a firm's strategy is entrepreneurial or conservative in nature (Morris, Webb, and Franklin 2011) and focuses on the firm's overall proclivity towards entrepreneurship (Lumpkin \& Dess, 1996). However, there is still vagueness in the literature on whether EO is "an attitude held by principals or executives, a set of firm behaviors, or some combination of the two" (Miller, 2011, p. 878).

There is also a lack of consensus on whether EO is a unidimensional or multidimensional construct (Covin \& Lumpkin, 2011). According to Miller's (1983) conceptualization, the EO construct is multidimensional and consists of three subdimensions: innovativeness, risk-taking and proactiveness. While all three subdimensions must be present to some extent, Miller also suggests that they may vary independently. The unidimensional perspective explains that the subdimensions associated with the EO construct covary (Dess \& Lumpkin 2005; Covin \& Slevin, 1991): others include competitive aggressiveness and autonomy (Dess \& Lumpkin, 2005). Based on the critiques of the Dess and Lumpkin conceptualization (Basso, Fayolle, \& Bouchard, 2009), and the use of the original three-dimension conceptualization by the majority of researchers (George \& Marino, 2011), this study adopts Miller's (1983) conceptualization. It utilizes the subdimensions of innovativeness, proactiveness and risk-taking, and examines how they vary independently to unpack the EO of entrepreneurial support spaces.

\subsection{Innovativeness}

Innovativeness is an essential part of the EO construct because it shapes how firms pursue new opportunities (Lumpkin \& Dess, 1996). Firm innovativeness may manifest in several ways (Lumpkin \& Dess, 1996) including technological innovativeness aimed at developing new products and processes, product market innovativeness, and administrative innovativeness (Dess \& Lumpkin, 2005). Several studies have implemented a range of approaches for measuring innovativeness (Hughes \& Morgan 2007, Covin \& Slevin 1989, Miller 1983), but the Covin and Slevin (1989) EO scale is the most widely used and measures innovativeness as the number of new products and services introduced across a 5-year period and changes in product or service lines.

\subsection{Proactiveness}

A variety of studies have operationalized proactiveness (Hughes \& Morgan 2007, Covin \& Slevin 1989, Miller 1983). Covin and Slevin (1989) and Hughes and Morgan (2007) suggest that proactive behavior manifests in a variety of ways in firms, examples of which include: the initiation of actions that elicit a competitor response, a first-mover advantage in the 
introduction of new products/services, proactive administrative actions, the proactive use of operating technologies, and the adoption of a competitive posture where a firm seeks to "undo its competitors". Lumpkin and Dess (1996) also suggest proactive organizations monitor trends, identify needs of existing customers, and anticipate changes in demand or issues that lead to new business opportunities.

\subsection{Risk-Taking}

Firms with an EO are often characterized by risk-taking behavior (Dess \& Lumpkin, 2005, p. 150). Risks may include venturing into the unknown, committing a large portion of assets, borrowing heavily (Lumpkin \& Dess, 1996), the introduction of new products into new markets and investing in new technologies (Baird \& Thomas, 1985). However, risk-taking may extend from a nominal level (e.g. depositing money in a bank) to highly risky actions (e.g. investing in unexplored technologies) (Dess \& Lumpkin, 2005). Lumpkin and Dess (1996) suggest that there are three types of risk-taking: business risk-taking, financial risk-taking and personal risk-taking. Business risk-taking refers to "the risk associated with entering untested markets or committing to unproven technologies" (Dess \& Lumpkin, 2005, p. 152). Financial risk-taking refers to the risk/return tradeoff (ibid). Personal risk-taking refers to "the risks that an executive assumes in taking a stand in favor of a strategic course of action" (Dess \& Lumpkin, 2005, p. 152).

Previous researchers have also operationalized firm-level risk-taking (Hughes and Morgan 2007, Covin \& Slevin, 1989, Miller, 1983). The Covin and Slevin EO scale measures if a firm has a preference for high-risk projects, undertakes bold, sweeping acts to achieve firm objectives, and adopts a bold, aggressive posture to maximize the probability of successfully exploiting new opportunities. Hughes and Morgan (1989) and Venkatraman (2007) measure risk-taking as the extent to which employees are encouraged to take risks with new ideas and/or projects.

\section{Entrepreneurial Orientation and Entrepreneurial Spaces}

Little is known about the innovativeness of newer types of entrepreneurial spaces including co-working spaces and accelerators. Incubator innovativeness has been explored previously as it relates to incubated firms (Clausen \& Korneliussen, 2012). However, it is hypothesized that innovativeness may manifest itself in different ways, particularly in new ways firms undertake their activities (Hughes \& Morgan, 2007). For example, Gertner (2013) found that an incubator's selection criteria changes over time to better accommodate the incubator's objectives. Incubator innovativeness can also be seen in the changes in services incubators provide to entrepreneurs (Gertner, 2013).

Aside from new ways firms undertake activities, the body of work from psychology, management, sociology, and design highlights the impact of physical workspaces on worker creativity Ceylan, Dul, \& Aytac, 2008). Thus, another way innovativeness is perhaps manifested in entrepreneurial spaces is through building and workplace design. Physical space has traditionally been an important part of the incubator offer and academic conversation (Vonzedtwitz \& Grimaldi, 2006). In relation to incubators and risk-taking, a 
recent study found risk taking to be one of six strategic drivers impacting the incubator's long-term development (Baraldi \& Havenvid, 2015). More broadly it has been suggested that incubator management involves balancing the conflicting goals of several stakeholders (Alsos, Hytti, \& Ljunggren, 2011). Additionally, as they are often largely dependent on public funding, conservative practices may be adopted to improve the perception of policy actors to gain increased income and demonstrate outputs (Aaboen, 2009).

\section{Conceptual Framework}

Figure 1 below illustrates a conceptual framework for characterizing the entrepreneurial orientation of the three types of entrepreneurial spaces in three-dimensions. In this figure, the $\mathrm{x}$-axis represents the proactiveness of a space, the $\mathrm{y}$-axis represents the risk taking propensity of a space, and the $z$-axis represents the innovativeness of a space. Based on this figure, it is possible to visualize the EO of each type of entrepreneurial space compared to others in terms of the three subdimensions of interest in this study. This provides a new means of visualizing the dimensionality of EO.

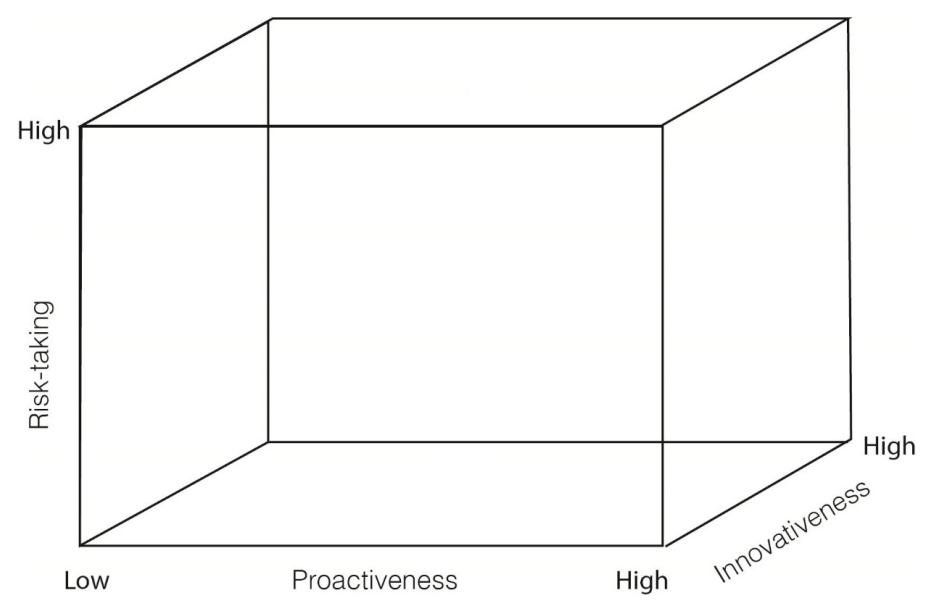

Figure 1. Conceptual Framework of Space Entrepreneurial Orientation (EO)

\section{Methodology}

To test for differences in the entrepreneurial orientation (EO) of_entrepreneurial support spaces, and the extent that these differences manifest according to various subdimensions of EO, a qualitative research strategy is used. This approach is appropriate for addressing questions about the why and how of EO that more quantitatively focused studies are unable to address (Miller 2011). The use of a qualitative approach also addresses the comparative lack of qualitative studies in the EO literature (ibid).

\subsection{Research Design and Selection of Cases}

A multiple case study approach to examine how entrepreneurial spaces differ in their EO was undertaken. This approach offers a stronger base for theory building and according to Eisenhardt and Graebner (2007:27) provides more "robust, generalizable and testable theory than single-case research". The entrepreneurial spaces for this study was determined by obtaining a list of business incubators from the National Business Incubator Association 
(NBIA). This list was cross-referenced and supplemented with the names of co-working spaces and accelerators from the Arizona Business Incubators Association (AZBIA) and the Arizona Commerce Authority (ACA). The completeness of this list was further verified by information provided by key stakeholders in the Phoenix entrepreneurial ecosystem. Phoenix makes for an interesting case study because it has experienced a rise in entrepreneurial activity after the recession of 2008 (Hoover, 2012).

Based on these lists, a total number of 52 entrepreneurial facilities were identified in the state of Arizona. Given that entrepreneurial spaces can be heterogeneous in terms of their strategies and objectives, (Aaboen, 2009), this study was designed to ensure that within different space types (e.g. co-working spaces), each space had similar objectives and represented the mission of a space type to facilitate comparisons. For example, all of the co-working spaces selected have the primary objective to foster serendipitous contacts between entrepreneurs. From the list of potential facilities, cases where narrowed down further based on the spaces' objectives. This left 3 co-working spaces, 3 accelerators, and 4 incubators for this study. Table 1 provides an overview of these spaces broken down by name, opening date, facility type, profit or non-profit status and how they are funded.

Table 1. Profile of entrepreneurial spaces

\begin{tabular}{|c|c|c|c|}
\hline Name & Opening Date & Facility Type & How Funded \\
\hline Space 1 & 2008 & Co-Working & Scope of work agreement with the city \\
\hline Space 2 & 2000 & Co-Working & Conventional financing \\
\hline Space 3 & 2011 & Co-Working & Membership fees \\
\hline Space 4 & 2010 & Accelerator & $\begin{array}{l}\text { Kauffman foundation, ASU VC received a } 1 \mathrm{MM} \\
\text { (federal stimulus) grant from the Governor's office }\end{array}$ \\
\hline Space 5 & 2008 & Accelerator & Sponsors and larger EO organization \\
\hline Space 6 & 2012 & Accelerator & $\begin{array}{l}\text { Arizona Commerce Association, Bioaccel; } \\
\text { funding from United States } \\
\text { Develonomic } \\
\text { Devent Administration (EDA) }\end{array}$ \\
\hline Space 7 & 2013 & Incubator & $\begin{array}{l}\text { Economic Development Administration, Maricopa } \\
\text { Community Colleges, City of Phoenix, \& Blue } \\
\text { Cross Blue Shield }\end{array}$ \\
\hline Space 8 & 2010 & Incubator & City government \\
\hline Space 9 & 2010 & Incubator & City government \\
\hline Space 10 & 2011 & Incubator & City government \\
\hline
\end{tabular}

Ten semi-structured interviews were conducted with the managers of the entrepreneurial spaces between January and September of 2013. In all, over 40,000 words $(49,959)$ of transcript text were collected. The interview questions were designed to obtain information regarding the risk-taking behavior, proactiveness and innovativeness of the spaces. These questions covered a range of topics including: the history and goals of the spaces, how 
managers differentiated themselves from other spaces, the technology assistance provided to entrepreneurs, and strategies for helping entrepreneurs adapt to technological change. The interviews were recorded and transcribed for analytical purposes.

The data were analyzed by following Eisenhardt's (1989) qualitative research methodology which involves a systematic process of familiarization, searching for cross-case patterns and emerging theory. The interview data was analyzed in NVivo to assign codes (see Table 2) based on the conceptual framework and prior work (Miles and Huberman 1984). The benefit of utilizing NVivo is that it enables the researcher to handle large amounts of data easily "enhancing transparency" and, therefore, it has been argued the quality of the findings and argument may be judged better (Crowley, Harre, and Tagg 2002:193). Finally, explanations were sought in order to test the two hypotheses of interest in this study- Are there differences in the EO of different types of organizational contexts that provide business support to entrepreneurs? How does the EO of these spaces vary across the subdimensions of EO?

Table 2. Coding Process and Categories of Nodes

\begin{tabular}{|c|c|}
\hline $1^{\text {st }}$-Stage Coding (Free Node) & $2^{\text {nd }}$ Stage Coding (Tree Nodes) \\
\hline Innovativeness & $\begin{array}{l}\text { Administrative innovativeness } \\
\text { - } \quad \text { Innovative methods firms utilize to operate their businesses } \\
\text { - } \quad \text { New ways of undertaking activities } \\
\text { Technological innovativeness } \\
\text { - } \quad \text { New product or service lines } \\
\text { - } \quad \text { R\&D technology leadership, innovations } \\
\text { Physical Space innovativeness (inductive theme) }\end{array}$ \\
\hline Proactiveness & $\begin{array}{l}\text { - Monitor trends, identify new needs of customers, anticipate changes in } \\
\text { demand that lead to new business opportunities } \\
\text { - } \quad \text { Adoption of a competitive undo the competitor posture } \\
\text { - } \quad \text { Initiates actions which force the competition to respond } \\
\text { - } \quad \text { First mover advantage in the introduction of products and/or services } \\
\text { - } \quad \text { Engagement with external organizations (inductive theme) } \\
\text { - } \quad \text { Continued monitoring of entrepreneurs after they exit spaces (inductive } \\
\text { theme) }\end{array}$ \\
\hline Risk-taking & $\begin{array}{l}\text { - Bold, wide ranging acts are necessary to achieve the firms objectives } \\
\text { - } \quad \text { Extent to which employees are encouraged to take risks with new ideas and } \\
\text { or projects } \\
\text { - } \quad \text { Preference for high risk projects } \\
\text { - } \quad \text { Adoption of a bold aggressive posture to maximize success of opportunities } \\
\text { - } \quad \text { Level of funding provided to entrepreneurs (inductive theme) }\end{array}$ \\
\hline
\end{tabular}

\subsection{Photographic Data}

Another source of data in this study is photographs taken of the entrepreneurial spaces of 
interest. These photographs were analysed because space could be considered an important aspect of facility innovativeness based on the body of research that suggests creativity is linked to innovation (Scott and Bruce 1994) and that interior design in corporate spaces also reveals organizational intentions (Ridoutt, Ball, \& Killerby 2002).

Table 3 summarizes eleven elements selected as indicators of space innovativeness. Of the 10 spaces of interest in this study, 8 gave permission to take pictures and 107 pictures were taken at 8 of these facilities. Two of the three accelerators did not give permission to take photos so accelerators were excluded from this phase of the space analysis. The analysis of these photographs involved analyzing them for the presence of the elements summarized in Table 3 and then coding the photographs for the presence/absence of these items based on similar analyses of photographic data (Lutz and Collins 1993, Rose 2001).

A space received a 1 if the item was present and a 0 if the item was absent and the scores for the individual items summed. The analysis produced a space innovativeness (SI) score of 0 to 11 for each of the spaces. A 0 indicates a space with an absence of creative elements while an 11 indicates a space with the presence of all the creative elements listed in Table 3 . This creation of a score based on the presence of creative elements is derived from Ceylan et al. (2008), who had informants rate photographs on an 11-point rating scale ranging from 0 to 10 of work environments that would be most conducive to creative problem-solving. A " 0 " indicated low potential for this kind of activity and a " 10 " indicated high potential for this kind of activity. In the coding of the photographs across each of these dimensions, several steps were taken to ensure intercoder reliability. These steps included multiple reviews of the codes by one author and the evaluation of these codes by a second author (Neuendorf, 2002).

Table 3. Indicators of Entrepreneurial Space Innovativeness

\begin{tabular}{|c|c|c|c|}
\hline Number & Element & Description & Prior Work \\
\hline 1 & Whiteboards & Presence of whiteboards & Landry (2012) \\
\hline 2 & $\begin{array}{l}\text { Open desk } \\
\text { arrangements }\end{array}$ & $\begin{array}{l}\text { Office layout that has shared deskspace, few } \\
\text { partitions or walls separating desks, and few } \\
\text { private office spaces }\end{array}$ & Toker and Gray (2008) \\
\hline 3 & Furniture & $\begin{array}{l}\text { Chairs, tables, cupboards that are placed in the } \\
\text { workplace with a novel design aspect }\end{array}$ & $\begin{array}{l}\text { Ridoutt et al. (2002); Dul, } \\
\text { Ceylan, and Jaspers (2011) }\end{array}$ \\
\hline 4 & Complexity & $\begin{array}{l}\text { Amount of structural elements in office space } \\
\text { (structural supports or beams, furniture, other } \\
\text { objects) }\end{array}$ & Ceylan et al. (2008) \\
\hline 5 & Clutter & Workspaces that contain the appearance of clutter & Vohs, et al (2013) \\
\hline 6 & Color & $\begin{array}{l}\text { Calming colors (green, blue, or blue violet) or } \\
\text { inspiring colors (yellow, orange, pink, red, or red } \\
\text { violet) }\end{array}$ & $\begin{array}{l}\text { McCoy and Evans (2002); } \\
\text { Ceylan et al. (2008) }\end{array}$ \\
\hline 7 & Art & Presence of pictures & $\begin{array}{l}\text { Bromberg (2014); } \\
\text { Jefferson Group (2015) }\end{array}$ \\
\hline
\end{tabular}




\begin{tabular}{|c|c|c|c|}
\hline & la & International Journal & $\begin{array}{r}\text { of Regional Development } \\
\text { ISSN 2373-9851 } \\
2017 \text {, Vol. 4, No. } 2\end{array}$ \\
\hline 8 & Natural materials & Presence of wood, brick, metal in the workspace & Ridoutt et al. (2002) \\
\hline 9 & Plants & Natural plants or flowers & Ceylan et al. (2008) \\
\hline 10 & Window views & $\begin{array}{l}\text { Visual access to the natural or any other outer } \\
\text { environment }\end{array}$ & McCoy and Evans (2002) \\
\hline 11 & Amount light & $\begin{array}{l}\text { Amount of light (natural or otherwise) in the work } \\
\text { environment }\end{array}$ & Ceylan et al. (2008) \\
\hline
\end{tabular}

\section{Findings}

\subsection{EO in Incubators}

Out of the three space types, incubators are the least innovative in terms of physical space and technological innovativeness, the latter of which was influenced by the entrepreneurs. However, they are the most proactive which was displayed in the activities they undertook to monitor trends, to identify the future needs of existing customers, to monitor clients after leave the space, to engage with external organizations and to outdo their competitors. Incubators are not risk-taking, instead, it is the entrepreneurs who are expected to take risks.

\subsubsection{Incubators and Innovativeness}

In relation to innovativeness, incubators did not display 'technological innovativeness' as it relates to R\&D technology leadership and innovations. Rather, the findings highlight that the entrepreneurs played an essential role in influencing the spaces' technological innovativeness. This included the sharing of new technologies, explaining tech terminology, and explaining how new programs and software work to incubator managers. The underpinning rationale for the entrepreneur's influence was down to the 'attitude' of incubator managers. They did not think it was their role to demonstrate leadership in such an area.

In comparison to newer types of spaces (e.g. co-working spaces and accelerators), incubators were found to be the least innovative as it relates to 'physical space innovativeness'. Table 4 and 5 present the results of the photo analysis for each of the spaces for which photo data were obtained. Based on the individual scores for each facility, an average score for the two facility types was computed. From these calculations, incubators received 5.3, which demonstrates that they are the least innovative. The difference between incubators and newer space types was explained further by interviews undertaken with the space managers. Managers of newer space types highlighted that space investments were tied to their organizational objectives. Unlike newer spaces, incubators do not have an objective of fostering serendipitous contact between entrepreneurs and therefore did not spend the time considering the innovativeness of their spatial environments. As an incubator manager highlighted:

"At the end of the day it's not about the space... an incubator...should just be a step above your garage...we're all about a program...it's a limited engagement, it's 2-3 years for a normal company"

Rather, space in an incubator context is about maximizing square footage to fund the model. 
One incubator manager explained:

"It's all about the square footage and we have got to maximize it in order to make the model work you got to maximize leasable square footage"

Table 4. Results of Photo Analysis: Co-Working Spaces

\begin{tabular}{|c|c|c|c|c|c|}
\hline & & Space 1 & Space 2 & Space 3 & \\
\hline Number & Element & Co-Working & Co-Working & Co-Working & Total \\
\hline 1 & Whiteboards & 1 & & 1 & 2 \\
\hline \multirow[t]{2}{*}{2} & Open & & & & \\
\hline & arrangements & 1 & & 1 & 2 \\
\hline 3 & Furniture & & 1 & 1 & 2 \\
\hline 4 & Complexity & & 1 & 1 & 2 \\
\hline 5 & Clutter & 1 & & & 1 \\
\hline 6 & Color & & & 1 & 1 \\
\hline 7 & Art & & 1 & 1 & 2 \\
\hline \multirow[t]{2}{*}{8} & Natural materials & & & & \\
\hline & & & 1 & 1 & 2 \\
\hline 9 & Plants & & & 1 & 1 \\
\hline \multirow[t]{2}{*}{10} & Window views & & & & \\
\hline & & 1 & 1 & 1 & 3 \\
\hline \multirow[t]{4}{*}{11} & Amount light & & & 1 & 1 \\
\hline & Total & 4 & 5 & 10 & \\
\hline & Overall & & & & \\
\hline & innovativeness & 6.3 & & & \\
\hline
\end{tabular}

Table 5. Results of Photo Analysis: Traditional Incubators

\begin{tabular}{lllllll}
\hline & & Space 7 & Space 8 & Space 9 & Space 10 & \\
Number & Element & Incubator & Incubator & Incubator & Incubator & Total \\
\hline 1 & Whiteboards & 1 & 1 & 1 & & 3 \\
2 & $\begin{array}{l}\text { Open } \\
\text { arrangements }\end{array}$ & & & & & \\
& Furniture & 1 & 1 & 1 & 1 & 4 \\
3 & Complexity & & 1 & & & 1 \\
4 & Clutter & & & & & 1 \\
5 & Color & 1 & & & 1 & 2 \\
6 & Art & 1 & 1 & & 1 & 3 \\
7 & Natural materials & & & & & \\
8 & & 1 & 1 & & 2 \\
9 & Plants & & 1 & 1 & 1 & 3 \\
\hline
\end{tabular}


Amount light

Total

Overall

innovativeness

\subsubsection{Incubators and Proactiveness}

While incubators were the least innovative, they were also the most proactive. This proactiveness was evident from their monitoring of trends. This included benchmarking themselves with existing incubators, visiting other spaces to learn about processes and best practices, looking at statistics from the National Business Incubator Association (NBIA) and undertaking studies to better understand what is/is not working in the incubator. One incubator manager highlights this point:

"Tempe has Sky Song and that works perfect for them with their students. Queen Creek is more of that bedroom community, home-based business...so we're just following those very infant stages of a community"

Incubators were also found to be proactive in identifying the future needs of existing entrepreneurs. This was achieved by learning from entrepreneurs about the services they require and by communicating with other incubators. One incubator manager explains this further:

"We've learned what works, what doesn't work and we still have things to learn. We learn from communicating with the other incubators and kind of learning from our entrepreneurs themselves from what they need and what assistance they really use, what has been beneficial, what has not"

Incubators were also proactive in monitoring entrepreneurs after they leave the space, an inductive theme, derived from the analysis. This included utilizing databases, engaging post exit, and developing alumni programs, all of which helped with the future sustainability of the incubators. An incubator manager describes this point:

"We reach out on a quarterly basis to our local companies to get a pulse on what they're doing in the market and what they're seeing and do they need help or are there any connections we can make or you know is there a product that just launched that we should be raving about for them on their behalf"

An inductive theme was the way incubators demonstrated proactiveness by engaging with external organizations. This included interactions with universities, entrepreneurs, CEOs, firms, local experts and other incubator managers - all of which helped with ensuring the delivery of quality services to entrepreneurs. Engagement with other incubators was found to be particularly important for incubators in regards to sharing knowledge, encouraging tenant 
interaction and problem solving. An incubator manager explained this point nicely:

"We all work together...there's a statewide association ... we just had a big

meeting...we're all in there talking war stories and 'oh man I had this client last week, he did this, and ah totally disrupted, and yeah we had the same thing you know'. It's our own little therapy group"

Finally, although it was found that incubation spaces were typically collaborating with each other, they also typically adopted a competitive undo the competitor's posture. They behaved in such a way to differentiate themselves, another indication of their proactiveness. An incubator manager explained:

“There's Sky Song, there's CEI, there's Tall Wave...there's like 6 or 7 within a 10-mile radius of us right there...were all trying to...make sure we're all differentiated enough to survive...it becomes a survival tactic at that point."

\subsubsection{Incubators and Risk-Taking}

In regards to the third dimension of risk-taking, incubators recognized that the entrepreneurs were taking risks; the role of the managers was to help support entrepreneurs with their risk-taking behavior. This was linked to the objectives and model of an incubator whereby this space type did not take an equity stake in companies; entrepreneurs were expected to acquire their own funding and were understood to be the ones undertaking all the risk. One incubator manager explained how this differs from the accelerator model, which places emphasis on equity:

"We're here because of those clients that are taking all the risks... So the major difference in [an] accelerator is usually an equity play. So the accelerator will take an equity stake in the company and...rapidly accelerate them through a process to get them commercialized as fast as they can. We don't do that here...we don't take any equities in our companies... They are the ones that are funding them, they are the ones that are going out and doing all the risk. We are here solely to support them doing great jobs for the region. It's a major, major difference. Accelerators focus on personal wealth and the accelerator model is a long term strategy model...It's a totally different model than us"

\subsection{EO and Co-Working Spaces}

Out of the three space types, co-working spaces are most innovative in regards to physical space design and the adoption of a strategic approach to technological innovativeness, which encourages and enables entrepreneurs to help each other. Unlike incubators, co-working spaces are somewhat proactive demonstrating just two of the six subdimensions of proactiveness. These subdimensions included the identification of future needs of existing customers and out doing competitors. Finally, co-working spaces are not risk-taking, which is related to their objective of fostering connectivity amongst entrepreneurs, as opposed to a financial stake in the venture or the provision o funding for entrepreneurs.

As it relates to innovativeness, co-working spaces took a more strategic approach to 
technological innovativeness. Whereby in incubators, the entrepreneurs indirectly influenced the technological innovativeness of the space. In this respect, co-working spaces encouraged and enabled entrepreneurs to help each other. This was a direct result of what one manager called a "pay it forward model"; tenants are encouraged to engage and share knowledge to sustain the community. A co-working manager explains:

"Not any formal technology assistance...we're really big about empowering our members to share with each other, so it might just be more, 'I'm running into this issue, can you help show me how you would do this within this program, or within this system, or how do you balance a budget, how do you hire, and fire people,",

Additionally, co-working spaces were more innovative in regards to physical space than incubators. This was demonstrated by the photographic analysis data, which highlighted that co-working spaces received a 6.3 in comparison to an incubator score of 5.3. Unlike incubators, these spaces demonstrated evidence of having window views, open-desk arrangements, and complexity. The interviews highlighted that physical space innovativeness was linked to co-working spaces' objectives to foster serendipitous contact between entrepreneurs and their recognition that space affects creativity. A co-working space manager highlighted this point:

"This is...more about your environment and the space...there's something really set for 25 foot ceilings and that head space it just changes the way you think about the world. I don't think this is the ideal place for a bunch of people who are...locked in on something...but if you're going to be...locked into the computer, then maybe this is not the best place",

Unlike incubators, co-working spaces were not as proactive. They rely more on unplanned, serendipitous interactions and therefore would not necessarily be expected to follow proactive planning practices. Out of the six subdimensions of proactiveness, co-working spaces only demonstrated two: identifying the future needs of existing customers and out doing competitors. A co-working manager explained how they identify the future needs of existing customers as it relates to help required for exiting the co-working space:

"We're trying to figure out what that next step is, and how we help facilitate the growth of not just our [space], but the businesses within because they're at that point now, we are hearing their concerns, and I'm not sure if they're just not comfortable with leaving the nest or if there just isn't a solution out there that makes sense yet, and maybe that means that we there needs to be a social created, that's a big question mark right now for us",

Co-working spaces did not exhibit risk-taking behavior compared to the other two space types. This was related to their community-oriented mission. One co-working manager highlighted this:

"We don't have very many members that request funding, but I think that's because that's just not something that we offer, so the people in here are just wouldn't ever request it, because they wouldn't stay here, if that's what they really needed"

\subsection{EO and Accelerators}


Accelerators are somewhat innovative, adopting a strategic approach to technological innovativeness by mobilizing internal and external resources, providing basic IT support and discussing the role of technology in the future of the start-ups. Similar to co-working spaces, accelerators are only somewhat proactive demonstrating two of the six subdimensions of proactiveness: engagement with external organizations and monitoring trends and identifying the future needs of customers. Finally, accelerators took the most risk. This is related to their objective to accelerate quickly the venture creation process by providing entrepreneurs with resources, including funding.

Similar to co-working spaces, accelerators also adopted a more strategic approach to technological innovativeness. While in the co-working model technological innovativeness was based on encouraging entrepreneurs to help each other, accelerators were very skilled at brokering and mobilizing not only internal resources for the benefit of their entrepreneurs but also external resources such as mentors. This was a result of spaces' objective to accelerate business growth by utilizing the skill set of external experienced mentors. One accelerator model explains this point nicely:

"The mentors are absolutely the key to the success for our accelerator, for almost every accelerator. You'll hear that and we've got great mentors...they're all have successfully started and sold companies and...they'll be sounding boards, they make suggestions, they open doors and make connections and they push the companies"

Similar to co-working spaces, this space type was somewhat proactive. Out of the six subdimensions of proactiveness, accelerators demonstrated only two: engagement with external organizations and monitoring trends. Engagement with external organizations and actors, an inductive theme which stemmed from the analysis, helped with the delivery of entrepreneurial knowledge to entrepreneurs. In particular, the use of mentors was an important resource utilized by accelerators to accelerate the entrepreneur's business idea, which also filled gaps in knowledge from managers. Accelerator proactiveness was also displayed in the monitoring of trends and identification of the future needs of existing entrepreneurs. This involved introducing new programs and services, and continuous analysis of the activities of other accelerators. An accelerator manager explained this nicely when he noted:

"I think if we had a little bit of lab space here that could be helpful. We've talked about trying to offer like a light manufacturing space... a shared space where we can actually have equipment or that the companies can buy their own equipment...but they can still have a place for their equipment and to do that work. So those are probably the two things and those like actually could be...in the same location and it would be helpful"

In regards to the third dimension of risk-taking, accelerators were the most risk-oriented. This is likely related to the business model of this space type, which is based on an equity stake in the companies accelerated, a long-term orientation on wealth creation, and a finite amount of time to accelerate a company. As regards risk-taking, accelerator managers adopted a 'bold, aggressive posture to maximize the likelihood of opportunity exploitation'. This included encouraging entrepreneurs to take risks in relation to experimentation on their services and 
products early on in the process to enhance their chance of sales. It also included encouraging entrepreneurs to build more sustainable companies based on early sales. An accelerator manager highlighted this point when he said:

"Lets bootstrap this thing, lets encourage our entrepreneurs to build and show attraction vey efficiently, very organically...those are how better companies are built and more sustainable companies are built at the back of validation not on the back of tens of millions of dollars in venture capital too early...So we need to move on, all of the startups that are here...we need to number one first and foremost, get those companies to figure out how to validate your subjects and sell something...I don't care what it is"

Along the same lines, accelerators also helped entrepreneurs to prepare for pitches to potential funders outside of the accelerator:

"We hope that some of them will be able to make request for agile investment or venture capital for Demo Day. And so we are trying to prepare them to make that ask and to know what they would use that funds for and to be able to answering the questions that potential investors might have"

An inductive theme that emerged from the interviews was that accelerators demonstrated risk-taking behavior by investing in companies. Unlike the other space types, they provide funding for companies to further accelerate and develop during their programs. One accelerator manager explained:

"So what that resulted in was a pool of funds for winning companies that was \$550,000.00 between the two funding partners... We had two rounds of judging, the final round included those teams pitching their idea and there was an eight-minute pitch to a panel of judges made up of the funding partners as well as the managers of the technology... and from that we awarded \$250,000.00 to 10 companies, \$25,000 per company"

\section{Discussion}

This study aimed to understand differences in the EO of various organizational contexts that provide business support to entrepreneurs including incubators, accelerators and co-working spaces. To do this, two hypotheses were tested:

H1: There are differences in the EO of different types of entrepreneurial support spaces such as incubators, accelerators and co-working spaces

H2: Differences in the EO of entrepreneurial support spaces varies across subdimensions of EO.

Regarding hypothesis one, the findings emphasize differences in the EO of incubators, accelerators and co-working spaces. Per hypothesis two, these differences in EO pertain to variations in the strength of the three main subdimensions of EO. Based on the conceptual framework for this study (Figure 1), these spaces may be organized in three dimensional space where each axis represents a subdimension of EO. Figure 2 is a diagram of this three-dimensional space that contains the facility types analyzed. Since incubators were the 
least innovative, most proactive, and did not take risks, this facility type is placed on the bottom right hand side of the figure. As accelerators ranked highest on their level of risk-taking, are somewhat innovative, and are somewhat proactive, this facility type has been placed in the top, middle of the figure. Finally, as co-working spaces are somewhat proactive, are not risk-taking, and are most innovative, this facility type has been placed in the bottom middle of the figure.

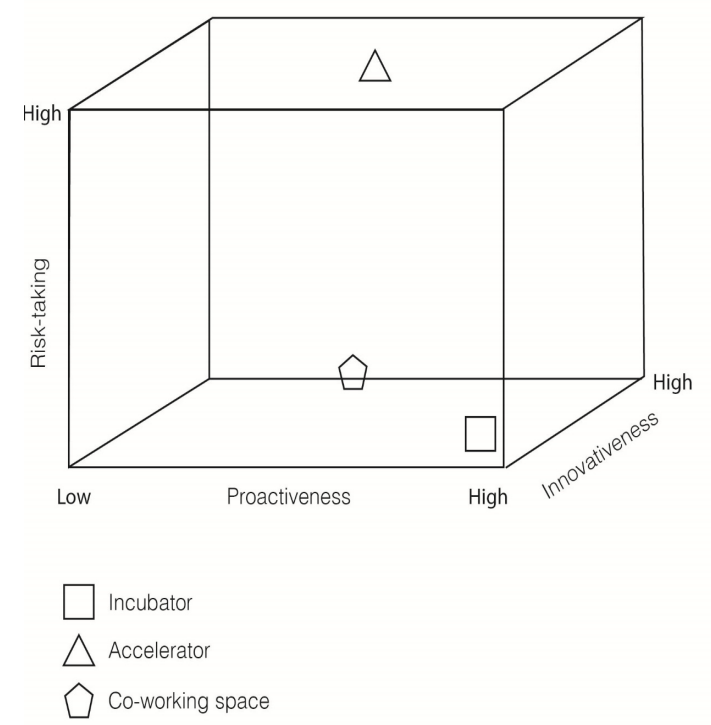

Figure 2. EO Dimensionality of Entrepreneurial spaces

As regards hypothesis two, variations in how the EO of entrepreneurial support spaces manifests across the subdimensions of EO demonstrate that the EO of firms and firm-like organizations is more complicated than the literature suggests. This unacknowledged complexity may be because the EO literature has "shied away from qualitative studies" (Miller 2011:886), which provide a more fine grained understanding of entrepreneurial behavior. For example, findings highlight that while some entrepreneurial spaces may be innovative in terms of their physical space, they are not necessarily innovative in relation to their emphasis on R\&D and technology leadership. This suggests that not only may the components of EO be more telling than aggregate indices or other composite measures of EO (Miller 2011), but also that within the subdimensions, there are differences that need to be considered for understanding entrepreneurial behavior. Our findings highlight the importance of adapting the EO scale to reflect differences in entrepreneurial behavior across different contexts (which is rarely done) (ibid) - in this case entrepreneurial spaces that provide support to entrepreneurs.

In addition to complex manifestations of EO across subdimensions, our findings suggest adding 'level of investment' as a new measure for the risk-taking subdimension for understanding 'financial risk-taking' by the spaces. For the proactiveness subdimension, two new measures are recommended: engagement with external organizations and continued 
monitoring of entrepreneurs after they exit spaces. These new measures are a telling way for understanding these spaces' entrepreneurial behavior. Entrepreneurial spaces typically rely on support from external organizations and actors to function (Hackett and Dilts 2004). The success of the entrepreneurs that exit these spaces is also important for entrepreneurial spaces to measure and promote their success to attract new entrepreneurs and funding.

Based on the study's findings, some policy implications can be discussed. There is an opportunity for new types of entrepreneurial spaces, to learn from the proactive behavior of older spaces, specifically, how they have been able to overcome some of the issues experienced by older spaces. The proactiveness of older spaces (e.g. incubators) is an indication of learning from knowledge accumulated over time and from spaces that failed. In contrast to newer spaces however, older spaces may want to reconsider their position on the importance of physical space provided to entrepreneurs given the link between physical space and worker creativity (Ceylan, Dul, and Aytac 2008). Space innovativeness appears to be a means for newer types of facilities (e.g. accelerators and co-working spaces) to meet their strategies and objectives of fostering serendipitous contacts between entrepreneurs. The impact of entrepreneurs on managers' innovativeness also indicates that this characteristic of entrepreneurs could be emphasized further in the selection of occupants by space managers.

\section{Conclusion}

Aside from these policy implications, a number of findings worth further exploration are possible. First, there is some evidence to suggest that EO was an attitude held by the managers of the spaces. Therefore, future research could further unpack whether EO is an attitude held by space managers or a set of firm behaviors, which is an open question in the literature (Miller 2011). Second, there was evidence of a potential link between the geographical context (e.g. Phoenix) and the organizational context (e.g. incubators, accelerators and co-working space) where the former influenced the latter's activities. Thus, future work could examine the link between different types of contexts which is a current gap in the literature (Zahra and Wright 2011). Finally, future work could explore EO within entrepreneurial space types. For example, further research could examine if the EO of different types of incubators such as tech incubators or more traditional incubators differed and how this impacts on the entrepreneurs they support.

That said, this article set out to provide one of the first analyses of variations in EO across different organizational contexts where context is defined as facilities that provide business support to entrepreneurs such as incubators, accelerators and co-working spaces. This analysis used qualitative evidence from semi-structured interviews and photos of incubation facilities to uncover important variations across facility contexts in the EO of these entities in terms of their innovativeness, proactiveness and risk-taking behavior. Given prior work which highlights that the EO of entrepreneurial spaces is related to the success of business incubation, the results of this analysis are important because they highlight subtle nuances in different space organizational models which are important to acknowledge in cultivating competitive entrepreneurial ventures. As the number of incubation facilities grows, these nuances are important to bear in mind as new innovations on the original business incubation 
model are created.

\section{Acknowledgements}

This research was funded by the Regional Studies Association (RSA) grant number 13054132.

\section{References}

Aaboen, L. (2009). Explaining Incubators Using Firm Analogy. Technovation, 29(10), 657-670. https://doi.org/10.1016/j.technovation.2009.04.007

Alsos, G. A., Ulla, H., \& Elisabet, L. (2011). Stakeholder theory approach to technology incubators. International Journal of Entrepreneurial Behavior \& Research, 17(6), 607-625. https://doi.org/10.1108/13552551111174693

Baird, I. S., \& Thomas, H. (1985). Toward a Contigency Model of Strategic Taking. Academy of Management Review, 10(2), 230-243.

Baraldi, E., \& Malena, I. H. (2015). Identifying New Dimensions of Business Incubation: A Multi-Level Analysis of Karolinska Institute's Incubation System. Technovation, 50, 53-68.

Basso, O., Alain, F., \& Veronique, B. (2009). Entrepreneurial Orientation: The Making of a Concept. Entrepreneurship and Innovation, 10(4), 313-321. https://doi.org/10.5367/000000009790012327

Bromberg, J. (2014). Engage the 5 Senses to Inspire Workplace Productivity. Retrieved April 18, 2014 from http://convene.com/engage-5-senses-inspire-workplace-productivity

Cashman, A. (2012). Coworking incubators: An Alternative for Startups. Retrieved from http://www.deskmag.com/en/hybrid-coworking-space-incubators-an-alternative-for-startups381

Ceylan, C., Dul, J., \& Aytac, S. (2008). Can the office environment stimulate a manager's creativity? Human Factors and Ergonomics in Manufacturing \& Service Industries, 18(6), 589-602. https://doi.org/10.1002/hfm.20128

Clausen, T., \& Korneliussen, T. (2012). The Relationship between Entrepreneurial Orientation and Speed to the Market: The Case of Incubator Firms in Norway. Technovation, 32(2), 560-567. https://doi.org/10.1016/j.technovation.2012.05.004

Covin, J. G., \& Dennis, P. S. (1989). Strategic Management of Small Firms in Hostile and Benign Environments. Strategic Management Journal, 10(1), 75-87. https://doi.org/10.1002/smj.4250100107

Covin, J. G., \& Lumpkin, G. T. (2011). Entrepreneurial Orientation Theory and Research: Reflections on a Needed Construct. Entrepreneurship, Theory and Practice, 35(5), 855-872. https://doi.org/10.1111/j.1540-6520.2011.00482.x

Covin, J. G., \& Slevin, D. P. (1991). A Conceptual Model of Entrepreneurship as Firm Behavior. Entrepreneurship, Theory and Practice, 16(1), 7-25. 
Crowley, C., Harre, R., \& Tagg, C. (2002). Qualitative research and computing: Methodological issues and practices in using QSR NVivo and NUD*IST. International Journal of Social Research Methodology, 5(3), 193-197. https://doi.org/10.1080/13645570210146258

Dess, G. G., \& Lumpkin, G. T. (2005). The Role of Entrepreneurial Orientation in Stimulating Effective Corporate Entrepreneurship. Academy of Management Perspectives, 19(1), 147-156. https://doi.org/10.5465/AME.2005.15841975

Dul, J., Ceylan, C., \& Jaspers, F. (2011). Knowledge workers' creativity and the role of the physical work environment. Human Resource Management, 50(6), 715-734. https://doi.org/10.1002/hrm.20454

Eisenhardt, K. M. (1989). Building theories from case study research. Academy of Management Review, 14(4), 532-550.

Eisenhardt, K. M., \& Graebner, M. E. (2007). Theory Building From Cases: Opportunities and Challenges. Academy of Management Journal, 50(1), 25-32. https://doi.org/10.5465/AMJ.2007.24160888

European Commission. (2002). Benchmarking of Business Incubators. Belgium: European Commission Enterprise Directorate General.

Fankhauser, D. (2013). The Pros and Cons of Startup Accelerators. Retrieved from http://mashable.com/2013/06/11/startup-accelerator-growth/

Foertsch, C. (2015). First Results of the New Global Coworking Survey. Deskmag. Retrieved from http://www.deskmag.com/en/first-results-of-the-new-global-coworking-survey-2015-16

George, B. A., \& Louis, M. (2011). The Epistemology of Entrepreneurial Orientation: Conceptual Formation, Modeling, and Operationalization. Entrepreneurship, Theory and Practice, 35(5), 989-1024. https://doi.org/10.1111/j.1540-6520.2011.00455.x

Gertner, D. (2013). Unpacking Incubation: Factors affecting incubation processes and their effects on new venture creation. PhD, Newcastle University Business School, Newcastle University.

Gust. (2015). Global Accelerator Report 2015. Retrieved from http://gust.com/global-accelerator-report-2015/

Harrison, J. D. (2012). Entrepreneurship advice: How to decide between coworking spaces, accelerators and incubators. The Washington Post October 22, 2012.

Hoover, K. (2012). Arizona No. 1 for startups, Kauffman study finds. Phoenix Business Journal.

Hubbard, J. (2013). The democratization of entrepreneurship: A case for coworking and collaboration. Retrieved

from http://www.slideshare.net/JonDanielEkh/the-democratization-of-entrepreneurship-a-case-forcoworking-and-collaboration 
Hughes, M., \& Robert, E. M. (2007). Deconstructing the relationship between entrepreneurial orientation and business performance at the embryonic stage of firm growth. Industrial Marketing Management, 36(5), 651-661. https://doi.org/10.1016/j.indmarman.2006.04.003

Jefferson Group. (2015). Art in the Workplace. Retrieved from http://jefferson-group.com/art-workplace/

Lumpkin, G. T., \& Dess, G. G. (2001). Linking Two Dimensions of Entrepreneurial Orientation to Firm Performance: The Moderating Role of Environment and Industry Life Cycle. Journal of Business Venturing, 16(5), 429-451. https://doi.org/10.1016/S0883-9026(00)00048-3

Lumpkin, G. T., \& Gregory G. D. (1996). Clarifying the Entrepreneurial Orientation Construct and Linking It to Performance. The Academy of Management Review, 21(1), 135-172.

Lutz, A., \& Collins, J. (1993). Reading National Geographic. Chicago: University of Chicago Press.

Markley, D. M., \& McNamara, K. T. (1995). Economic and fiscal impacts of a business incubator. Economic Development Quarterly, 9(3), 273-278. https://doi.org/10.1177/089124249500900307

McCoy, J. M., \& Evans, G. W. (2002). The potential role of the physical environment in fostering creativity. Creativity Research Journal, 14(3-4), 409-426. https://doi.org/10.1207/S15326934CRJ1434_11

Miles, M. B., \& Huberman, A. M. (1984). Qualitative Data Analysis. Thousand Oaks, CA: Sage.

Miller, D. (1983). The Correlates of Entrepreneurship in Three Types of Firms. Management Science, 29(7), 770-791. https://doi.org/10.1287/mnsc.29.7.770

Miller, D. M. (1983). Revisted: A Reflection on Eo Research and Some Suggestions for the Future. Entrepreneurship Theory and Practice, 35(5), 873-894.

Moriset, B. (2014). Building new places of the creative economy: The rise of coworking spaces. In 2nd Geography of Innovation International Conference. Utrecht University.

Morris, M. H., Justin, W. W., \& Rebecca, J. F. (2011). Understanding the Manifestation of Entrepreneurial Orientation in the Nonprofit Context. Entrepreneurship, Theory and Practice, 35(5), 947-971. https://doi.org/10.1111/j.1540-6520.2011.00453.x

NBIA. (2012). Business Incubation FAQ. Retrieved from http://www.nbia.org/resource_library/faq

Neuendorf, K. A. (2002). The Content Analysis Guidebook: Sage.

Ridoutt, B. G., Ball, R. D., \& Killerby, S. K. (2002). First impressions of organizations and the qualities connoted by wood in interior design. Forest Products Journal, 52(10), 30-36. 
Rose, G. (2001). Visual Methodologies. London: Sage Publications.

Scillitoe, J. L., \& Alok, K. C. (2010). The Role of Incubation Interactions in Assisting New Ventures. Technovation, 30(3), 155-167. https://doi.org/10.1016/j.technovation.2009.12.002

Scott, S. G., \& Bruce, R. A. (1994). Determinants of innovative behavior: A path model of individual innovation in the workplace. Academy of Management Journal, 37(3), 580-607. https://doi.org/10.2307/256701

Toker, U., \& Gray, D. O. (2008). Innovation spaces: Workspace planning and innovation in US university research centers. Research Policy, 37(2), 309-329. https://doi.org/10.1016/j.respol.2007.09.006

Vanderstraeten, J., \& Paul, M. (2012). Service-based differentiations strategies for business incubators: Exploring external and internal alignment. Technovation, 32, 656-670. https://doi.org/10.1016/j.technovation.2012.09.002

Vohs, K. D., Redden, J. P., \& Rahinel, R. (2013). Physical order produces healthy choices, generosity, and conventionality, whereas disorder produces creativity. Psychological Science, 24(9), 1860-1867. https://doi.org/10.1177/0956797613480186

Vonzedtwitz, M., \& Grimaldi, R. (2006). Are Service Profiles Incubator Specific? Results from an Empirical Investigation in Italy. Journal of Technology Transfer, 31(4), 459-468. https://doi.org/10.1007/s10961-006-0007-7

Zahra, S. A., \& Mike, W. (2011). Entrepreneurship's Next Act. Academy of Management Perspectives, 25(4), 67-83. https://doi.org/10.5465/amp.2010.0149

Supplemental Information: Detailed quotes, organized by EO subdimension for the three space types.

Table 6. Representative quotes for Incubators and EO Subdimensions

\begin{tabular}{|c|c|}
\hline EO Dimension & How manifested in Incubators \\
\hline Innovativeness & Space 7 \\
\hline Technological innovativeness & “They're talking technology that I don't understand” (Jeff) \\
\hline - $\quad$ Emphasis on R\&D technology & \\
\hline leadership and innovations influenced by & Space 8 \\
\hline \multirow[t]{8}{*}{ entrepreneurs } & "So I know when we have tech questions I'm not as tech savvy as others are...I go to a company that's usually who I \\
\hline & turn to one of our tenants and say you know help me understand what this is” (Mitchell) \\
\hline & Space 9 \\
\hline & "I'll look at something and think how do they like, I am not on this same level with them, but I am so eager to \\
\hline & learn...It's actually fascinating the technology that is out there that keeps coming out”(Julie) \\
\hline & Space 10 \\
\hline & "If it's their computer just doesn't seem to be booting up correctly, that's not our issue and we don't help with that \\
\hline & type of thing” (Kim) \\
\hline Proactiveness & Space 7 \\
\hline $\begin{array}{l}\text { Monitor trends, identify future needs of } \\
\text { existing customers and anticipate changes in }\end{array}$ & $\begin{array}{l}\text { "We're starting our student business incubation program here in about } 2 \text { months, so students from all over the } 10 \\
\text { community colleges here in the Maricopa district can all come in and we'll ramp them right through the same }\end{array}$ \\
\hline
\end{tabular}


demand or problems that can lead to new venture opportunities

Continued monitoring post-exist

Engagement with external organizations

Typically adopt an out due the competitors program ... and then we're going to be doing youth entrepreneur camps this summer for the high school level” (Jeff) Space 8

'I think we'd like to provide more connections with the C firms. You know it's one of those markets that you know we're doing our best to make, you know I met with two or three of them last night and you know how do we continue to network with them and make introductions to our clients...So that's something first thing I would like to be able to provide more" (Mitchell)

Space 9

"Learning from our entrepreneurs themselves from what they need and what assistance they really use, what has been beneficial, what has not, what types of mentors do work, what do not, things like that" (Julie)

Space 10

"I would like to provide more educational opportunities that truly takes their business to that next level. I know that small business development center actually has classes called "Next Level". It's a 12 week course and they literally say here's where you are now, here's where you want to be, let us help you get there. And so that's something that I would like to offer them" (Kim)

Space 7

"We still capture that job creation after they graduate because we fill that's what we get judged on. We fill that we're still a part of them, we still, you know we'll still bring in once a quarter to say do a check in, how's your business going? Well I'm still struggling with that marketing issue that I had before when I was in the incubator and so we stayed very closely with our-you know very close to our graduates" (Jeff)

Space 8

"You know we do this on a quarterly basis and so our goal is you know when they do graduate and if they do stay in Chandler and fingers crossed they do we have an open dialogue with them and I can honestly say that I know just about everyone in this building and all the decision makers within each company and so you know when they do graduate I'm going to continue that open dialogue with them" (Mitchel)

Space 9

"In the next year because all the contracts have been either three to five years" (Julie)

Space 10

"We had a business called X... When she left after 10 months, she had 26 employees. So at about the seven month range, eight month range, we realized you got something pretty good going on here and we found a perfect space for her...we let her out of her contact and helped her find that facility and kind of bridged her and the owner together. And they're doing fantastic now and it's just right across the street and to the north a little bit"' (Kim)

\section{Space 7}

"We're in an industry that we can all help each other. Like X when he first got down here to run X he called me up and said hey you know I need a client or a client handbook, and so I sent him my client handbook in electronic form so he could go in and change it all up and you know so we're here to help each other. We don't want to see anybody fail...Because if one fails that really puts a bad mark on all the rest" (Jeff)

Space 8

“We've got great partnerships with Intel, with other start-up companies that have made it big...You know we've got great connections with very large corporate companies that are housed in Chandler that when one of our tenants needs help and we have an opportunity to pair them with them. We make the connection for them. We help find what they're looking for and do our best"' (Mitchell)

Space 9

"Collaboration with other incubators I think is really important. We had an instance where we took a group of entrepreneurs from here up to NESAC and two of the guys actually hooked up and worked on a project together. So it's pretty amazing, the talent and what they bring out in each other. So I think that actually is very important" (Julie) Space 10

"We also have what we call a small business resource team and that is made up of professionals in the community that have offered their services free of charge. So we try to link any of the business and their needs with the right person" (Kim)

Space 7

“We're focused on technologies in the bio technology space. Clean energy, software development, and we're really focused on entrepreneurs that are coachable. Companies that are going to create jobs, that's what we get graded on, on a daily basis" (Jeff)

Space 8

“We've got great partnerships with Intel, with other start-up companies that have made it big...we've got great connections with very large corporate companies that are housed in Chandler that when one of our tenants needs help 


\section{Macrothink Mnstitute}

posture

and we have an opportunity to pair them with them. We make the connection for them" (Mitchel)

Space 9

"We are all just different...we have a lot of space. We may not have a lot of seed money but we focus on what we do have which is city support, space and a little bit of flexibility. We 've put together some great mentors" (Julie)

Space 10

"In our community, having the actual space at a reasonable price, giving them a chance to grow before they go out into the community. We have a lot, several businesses who may be established in another community that would like to come to Queen Creek but they're just not quite sure if they can make it or not. So before they go and sign a five year lease, we give them a chance to come here and grow their business and see what their actual base is going to be before they go out and sign that five year lease" (Kim)

\section{Risk-taking}

Entrepreneur taking risk

Table 7. Representative quotes for Co-working spaces and EO Subdimensions

\begin{tabular}{l} 
EO Dimension \\
\hline Innovativeness \\
Technological innovativeness \\
Emphasis on R\&D technology \\
leadership and innovations \\
encouraged by entrepreneurs \\
helping each other
\end{tabular}

\section{Proactiveness}

Monitor trends, identify future needs of existing customers and anticipate changes in demand or problems that can lead to new venture opportunities

\section{How manifested in Co-working spaces}

Space 1

"I mean that for instance it's not just, you know, it's not...an incubator, there is quite a bit more giving towards the community, that routine" (Trish)

Space 2

"I think most of the companies here are pretty cutting edge, and so again it's that exposure just by...osmosis...through our -- there's a Facebook has it on neat function called private pages, so there's a X members, you know, private page that we interact on and calendar things and keep each other informed and we -- you can stored documents on it and, you know, it's really great to just -- to be able to find out the cutting new thing by the new company that's in here, you know"(Wayne)

\section{Space 3}

"For the entrepreneurs within our space...we also create a community that, or a culture, we create a culture here of sharing, giving collaboration, and everybody is expected to exude those characteristics, and when you're open, and you're caring, and you're sharing you never know where your business can take off, people are constantly trying to help you, you always are open about your problems, and other people are now willing to help create a solution for you, and you just are in an atmosphere where you're not alone anymore, so for our entrepreneurs within Co-Hoots that's our goal for entrepreneurs" (Jenny)

\section{Space 1}

"We do and it's consistently changing I think that is kind of uniqueness of it is that we were very fluid and agile” (Trish)

\section{Space 2}

"I think there are places that are doing it differently that really works better for certain areas, for us we can -- we have three architecture firms here that really seem architecturally seem to love that... We have...video and photography and we have...those amenities that other places don't have. I think we are, you know, there is I think a lot of the co-working places are really it seems to me from what I've seen, you know...there's a lot of coders and, you know, a lot of backend computer stuff that goes on for a lot of the entities within those other co-working spaces and, although we have some people that do that here I don't think that, that's what this place is geared for it's not like all right put the blinder down and get into the machine" (Wayne)

Space 3

"We did a survey, on this a lot of them say marketing, which can mean so many things, but to me its visibility, making sure that their company is visible to all opportunities...that's what they're struggling with, I'm sure there's other things to just like straight marketing, straight designs, start straight branding, start straight, communication" (Jenny)

\section{Space 1}

"The space out there everything that's out there can be move back into these conference rooms and then that becomes another space. 


\section{Macrothink}

International Journal of Regional Development

ISSN 2373-9851

2017, Vol. 4, No. 2

Typically adopt an out due the competitors posture

And we'll do smaller events like our brown bags just out there but then they'll do larger events...everything from that space can be moved on and then we can have over a 100 people on that" (Trish)

\section{Space 2}

"Differentiate yeah...there's the art component it makes it very different, you know, we have two galleries here, people come. First Friday, third Friday not to -- we get on a first Friday we might get 10,000 people to the door one night...we're constantly in the news for one thing or another" (Wayne)

\section{Space 3}

"I think there is lot of workspaces out there there's tons that are shared workspaces, but what makes us really different is we have that passion for the community around us, and we've worked really hard to grow our community, we've worked really hard to find people who are passionate about what they do, and passionate about this model of working together" (Jenny)

Risk-taking Space 1

"It hasn 't really been a huge concern ... you know, we don't provide funding" (Trish)

\section{Space 2}

"I can't stress you know, somebody comes in and they don't want to co-work, they don't want be -- they don't want help other people as they help themselves, they don't get the fact, if they don't understand the concept that by -- that not everything that you do is measured in dollars per hour that the good relationships you build... and you really need to be able to work well with others to be here. So if you don't work well...you shouldn't be here, you know (Wayne)

\section{Space 3}

"The idea is to take less stress away...and let entrepreneurs focus on what they really should be focusing on, which is their business" (Jenny)

Table 8. Representative quotes for Accelerators and EO Subdimensions

EO Dimension
Innovativeness
Technological innovativeness
Emphasis on R\&D technology leadership and innovations
encouraged by other entrepreneurs and mentors; basic IT
support
How manifested in Accelerators

\section{Space 4}

"It's mentor driven....we understand that we as the investors as the managers of the cohort don't have all the answers, we're never going to have all the answers because we have such despaired group of companies coming in. So mentorship is absolutely a key because you never know within our group of 200 mentors who's going to have the right answer to that specific question that we could have never foreseen...So by having a really deep mentoring pool...we've got over 200" (Brent)

\section{Space 5}

"We have had a lot of conversations within the groups them using certain software and changes on software that's coming so soon like CRM systems or something that we will talk about it and say hey I'm using this it worked kind of great for me so share that to the group so that usually makes some them to change or consider to change" (Robert)

Space 6

"We've got probably 2,000 mentors that are working with these different companies" (Wiley)

\section{Space 4}

\section{Proactiveness}

Monitor trends, identify future needs of existing customers and anticipate changes in demand or problems that can lead to new venture opportunities

“When you go out you talk to X and X and you know all these other places they're picking up on it's just the same time we are, so it's really exciting” (Brent)

\section{Space 5}

"We've now introduced...systems where we have eight or ten accelerated members who are looking for somebody on a one on one basis again to help them grow the business so we introduce them and the advantage is that so that has never been working the last three to four months" (Robert)

Space 6

"We've talked about trying to offer like a light manufacturing space so kind of a shared space where we can actually have equipment... So those are probably the two things and those like actually could be at the same -- in the same location and it would be helpful" (Wiley) 
Space 4

"We're actually charter members of the global accelerator network that was founded in Mogote, Colorado by one of the world's leading accelerators TechStars" (Brent)

\section{Space 5}

"We have a facility that comes in and he will talk about different things that they will experience here. We will bring in a couple of speakers, we will bring in an ex-senior manager with the IRS just to talk about you know the peak holes and some of the things to watch out for and then we will bring in a CP from Neola to talk about financial related issues. So that's how we give out the content and deliver" (Robert)

\section{Space 6}

“We've got some funding from the US Government, the EDA to be able to pay those super mentors...they're all serial entrepreneurs that have been through all of the struggles that started companies" (Wiley)

\section{Risk-taking}

Typically adopts a bold aggressive posture in order to maximize the probability of exploiting potential opportunities

\section{Space 4}

"I'm sitting here preaching to all these companies like, you know, build, test, learn, build, test, learn" (Brent)

Space 5

"The main goal is to just try and get them to a million dollars... Yeah such high goals" (Robert)

Space 6

"We do provide cash... a normal license agreement will have a low single digit percentage ownership in the company" (Wiley)

\section{Space 4}

"If you're an entrepreneur and you get accepted...you kissed your wife or your dog or your husband good bye and you say I'm going to make this work or not, and I'm going to summer camp for three months or six months, and if I don't, you know, have a successful exit whether I raise a significant PC round to put food on the table for the next five years or I don't make, you know, several sales by the end of this thing or I don't go public then I give my best shot" (Brent)

\section{Space 5}

"I think just again the way entrepreneurs think...they will always want to be ahead of the game and simply all entrepreneurs have developed that mentality” (Robert)

\section{Space 6}

"We don't write their business plan... We 're there to assist them but it's their company, it's their business they've got to do that so we don't write business plans...the actual day-to-day work that they have to do it for their company is not what we do" (Wiley)

\section{Copyright Disclaimer}

Copyright for this article is retained by the author(s), with first publication rights granted to the journal.

This is an open-access article distributed under the terms and conditions of the Creative Commons Attribution license (http://creativecommons.org/licenses/by/3.0/). 